\title{
Unmediated is the Message: Enhancements to Traditional Interlibrary Loan in a Canadian University
}

\section{Ophelia Cheung}

Ryerson University

\section{Susan Patrick}

Ryerson University

\section{Please Cite:}

Cheung, O., \& Patrick, S. (2004). Unmediated is the message: Enhancements to traditional interlibrary loan in a Canadian university. Interlending \& Document Supply, 32(3), 152-158.

doi:10.1108/02641610410551978

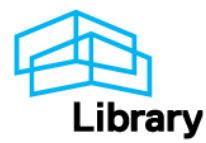




\title{
Unmediated is the message: enhancements to traditional interlibrary loan in a Canadian university
}

\author{
Ophelia Cheung and Susan Patrick \\ Librarians at the Ryerson University Library, Toronto, Ontario, Canada
}

\begin{abstract}
This paper discusses the implementation and delivery, at Ryerson University Library in Canada, of three consortially-facilitated, user-centered initiatives to enhance traditional interlibrary loan services. Through a collaborative purchase of approximately 4,000 NetLibrary ebooks, with the Ontario Council of University Libraries (OCUL) consortium and the Consortium of Ontario Libraries, the Library provides unmediated access to shared monographs. Ryerson's fullysubsidized document delivery service allows users to order journal articles directly from the Canada Institute for Scientific and Technical Information (CISTI Source) database.
\end{abstract}

\section{Introduction}

Ryerson University, in Toronto, Ontario, Canada, is a leading centre of career-focused education. The Ryerson Library collection consists of over 500,000 books, 2,500 print journal titles and over Can $\$ 1$ million is spent annually on electronic resources. This is a relatively small print collection - hence, the importance is of consortial resource sharing, collective purchasing, interlending and document delivery. These efforts have been enabled particularly through our participation in The Ontario Council of University Libraries (OCUL), a consortium of 20 university libraries in the Province of Ontario, who cooperate to enhance information services. By 2000, OCUL had already made consortial purchases of a number of electronic databases and achieved substantial cost-savings for the Ryerson Library.

David H. Fuller, Jr discusses the relationship between distance education, technology, educational trends, and library services (Fuller, 2002). The Internet has increased faculty and student access to resources outside the walls of the library. The emphasis on speed and convenience in the digital age penetrates every facet of our life, from fast food delivery to the door within guaranteed time, to no-waiting wireless access to the Web, and to integrated voice, e-mail, Web functionality in a compact cellular phone.

Traditional interlibrary loan services are simply not enough to meet the needs of the new generation, and must adapt to keep pace with these changing demands. Like many other libraries, Ryerson Library has re-thought and redefined its services in relationship to the educational needs of its users. The library has striven to provide 24/7 access to a significantly expanded collection of full-text electronic databases and ebooks, and instant reference assistance through an interactive "chat" service. An electronic reserve system is being implemented. The library is also interested in pursuing digital image databases and Web streaming of video. Improved document delivery and interlibrary loan are just other aspects of library service which provide the users with the convenience and speed of accessing information at the point of need. 


\section{netlibrary eBooks}

netLibrary eBooks is an OCUL consortial digital initiative which provides unmediated access to shared virtual monographs. NetLibrary eBooks are full-text electronic versions of books previously published in print, in a wide range of subjects etc. Access to these ebooks is through the Web, with no additional software or hardware required.

The OCUL consortial purchase of netLibrary eBooks is a concept that could be described as sharing the virtual as opposed to the traditional ILL role of lending of the physical. The advantages of shared ebooks are many: user convenience of having remote unmediated instant access 24/7; cost/labour saving, as no staff time is involved in the process; additional cost saving as the collaborative purchase resulted in a far lower price per title for each library.

The idea of shared ebooks was not new. Several American consortia had been operating on this model. The Tampa Bay Library Consortium in Florida began acquiring and making accessible netLibrary eBooks in September 2000. They have reported a favourable outcome in terms of content and use, and were ready to move ahead in this area (Cannon and Watson, 2001). Nylink in New York State began a consortial acquisition of a collection of netLibrary ebooks in June 2000. They have been more cautious about the success of their venture, noting that while ebooks may be here to stay, their potential impact is still in its infancy (Lynch, 2001/2002). In Colorado, both Colorado Alliance of Research Libraries and Bibliographical Center for Research provide shared access to netLibrary eBooks, and the usage was found to be significant (Littman, 2002). A study of usage of netLibrary eBooks in the Wisconsin Public Library Consortium found users' response to be positive (Conhaim, 2003). A literature review shows that the number of consortia offering shared ebooks has been increasing.

OCUL purchased 2,000 netLibrary titles in March 2001, obtaining perpetual rights (rather than annual rights) for access. Each participating library identified the Library of Congress classes relevant to their curricula and collection development policies. Titles were then chosen from lists of Canadian presses, Choice Outstanding Academic Titles, The Council of Prairie and Pacific University Libraries in Canada (COPPUL) selections, and netLibrary's business titles. This preliminary list of selections was then circulated to participating libraries for potential eliminations, and a final list was compiled. One copy of each title is shared between the participating libraries. A cost-sharing formula, based partially on FTEs, was developed, and Ryerson paid a very low cost per title. The statistics on the number of "turn-aways" (see below) show a success rate of 86.5 per cent which compares favourably with the results of a Materials Availability Survey undertaken by the Ryerson Library, where the success rate for finding physical items on the shelf was 74 per cent (adjusted to remove searches for items not found in the OPAC) (Ryerson University Library, 2000). These statistics indicate that this shared mode is currently adequate for our users needs.

In October 2002, the original OCUL consortium was joined by the Consortium of Ontario Libraries (COOL) to purchase additional titles over the next few years. The COOL participants in this project are select public libraries of the Southern Ontario Library Service (SOLS) and the Bibliocentre, which represents the Ontario Community Colleges. OCUL was given access to the COOL titles, and COOL to the OCUL titles, at no additional cost to either consortium. As a 
result, Ryerson now has approximately 4,000 netLibrary eBooks. The acquisition of this electronic collection was the first time in Canada in which both public and academic libraries have worked collaboratively (McDonald, 2003).

The netLibrary purchase has enhanced the Ryerson Library collection through new titles and additional copies, with relevant content. (netLibrary usage statistics reports, the results of checking of bibliographies for recent collection evaluations, and subjective observation of the use of ebooks in the Reference area of the Library, have substantiated this claim.)

One of the key factors in the users' easy adoption of ebooks has been that they are fully integrated into the library catalogue. NetLibrary provides MARC records, compatible with the Innovative Interfaces integrated system used by the Ryerson Library, and these were loaded into our Web OPAC.

Ryerson users will typically find an ebook through the Ryerson Library catalogue by subject, keyword, title or author search. Our catalogue can also be searched by added author "netLibrary" for an alphabetical listing of these ebooks. (Alternatively, users can search through the netLibrary Web site www.netlibrary.com, which has the additional enhancement that the full-text of the books are keyword searchable.) Ebooks may be accessed in two ways: browsing or checkout. Users can browse online for an unlimited time: while the user is actively using that ebook, no other user will have access to it. If 15 minute elapse without active use, the connection is lost and the book is virtually returned to the shelf. Access is validated through IP authentication. Off-campus users connect through ezProxy for remote use, as they would do for other Ryerson databases.

Users may also create a free account online on an IP authenticated computer and then have access to the collection through the netLibrary Web site from any location worldwide, without IP authentication. Account holders are able to check out titles for a two-hour loan period for exclusive online reading, but usage statistics indicate that most users spend an average of 5-15 minutes on a title. As these books are being consulted for research, rather than leisure reading, users will typically quickly browse the table of contents, then access a specific section and printout or copy the pages they want for off-line reading. The software does not allow downloading and printing/copying must be done page by page.

The statistics and unofficial feedback from our users indicate a positive response to the ease of use, quality content and availability of our collection of netLibrary eBooks.

Statistics for two and a half academic years (September 2001 to December 2003) are as follows:

- over 1,500 accounts created (but accounts are not necessary for browsing access);

- different titles accessed;

- total accesses: 9,368;

- turn-aways: 1,266 ; and

- $\quad$ usage: range from 174 uses per title to 0 


\section{CISTI Source document delivery}

Ryerson's fully-subsidized document delivery service allows users to order journal articles directly from the Canada Institute for Scientific and Technical Information (CISTI Source) database. Unlike most document delivery projects in North America, massive journal cancellations were not the main driving force behind Ryerson Library's pilot project in offering CISTI Source. Service enhancement and convenience to users were the prime considerations.

The official change from a polytechnic institute to university status in 1993 and the resulting increase in research activities have accentuated the need for access to scholarly literature beyond the Library's local holdings. Despite significant acquisitions in electronic full-text databases, the expanded journal collections are inadequate for the breadth and depth of research needs. The change from a fee-based to a fully subsidized interlibrary loan service in November 1997 addressed a main concern of users in conducting research - the cost of getting materials. Time is the next important issue. A benchmark study by the New Mexico State University in the United States indicated that a majority of users believe that copies should arrive faster than loans and expect delivery within 48 hours (Stabler, 2002). However, according to a 1996 ARL Performance Measures Study of research and college libraries, the average turnaround time to fulfil a borrowing request for copies in the traditional ILL setting was 15.6 calendar days for research libraries and 10.8 days for college libraries (Jackson, 1998a, b). At Ryerson Library, the average borrowing turnaround time for copies in 1998 was 13.8 days (from the time a request is entered on the ILL system, to checking-in an item). In 2001/2002, the average was improved to 6.6 days. This was partly due to an increase in the ILL staff complement and the adoption of new technologies - the Ariel software for scanning and transmitting documents and the use of AVISO, the automated ILL Management System. However, achieving turnaround time of 48 hours could not be guaranteed. Choosing a document delivery service provider with a credible track record of fast turnaround time was the next logical direction for service enhancement.

CISTI Source was the prime choice. Firstly, it guarantees 48-hour turnaround time. Secondly, CISTI Source is a Canadian database, covering more than 17,000 journal articles in the scientific and engineering disciplines. Over 70 per cent of the journal titles requested by the top borrowing departments in 1999/2000 were listed in CISTI Source. Furthermore, Ryerson could benefit from the OCUL negotiated rate of Can\$7.50 per article, a 25 per cent discount from CISTI's posted rate of $\$ 10$. The cost compares favourably with the average ILL charge. The OCUL group members charge one another Can $\$ 5$ for articles. The cost is much higher if the requests have to go outside the province or the country, as much as US \$20 in some instances. This does not even include the hidden cost of staff processing, which could be several times higher than the fees charged by lending institutions.

Ryerson Library has benefited from the experiences of other libraries that offer document delivery service to their users. Attention was paid to user training and linking the library's periodical holdings to the CISTI Source database to prevent unnecessary ordering of materials owned by the Library. Ariel delivery was preferred over fax because it provides better quality copies, especially for graphics and charts. Ryerson staff wanted to evaluate CISTI Source's performance by keeping a log of its turnaround time and inspecting the quality of articles received. Therefore, requested articles are delivered to the Library's Ariel machine. Users 
subsequently pick them up at the Circulation desk. However, faculty can request articles to be sent to their offices via campus mail.

It was soon discovered that everything learned could not be applied without a constant reassessment of local culture and users' needs, and rethinking of the project parameters. Initially, Ryerson ILL offered the CISTI Source service only to the science and engineering faculty. Cited studies have supported the view that science users would find the service most beneficial (Row et al., 2001). This group of users would probably mostly need current information and need it fast. In anticipation of enthusiastic response, ordering was limited to 15 articles per user during the six-month trial period.

This restriction proved to be unnecessary, however, as users did not initially overuse the new service. Since both ILL and CISTI Source service are free to the user, cost was not a consideration in choosing either service. Some heavy ILL users were accustomed to mediated service; they were content to be served. They requested ILL well in advance of their needs. Hence, the "just in time" selling point of CISTI Source ordering had limited appeal for them. Although the database is linked to the Ryerson Library catalogue, preventing users from requesting Ryerson holdings and connecting them directly to the Library's full-text resources, the two collections were only able to be compared at the title level and not volume and issue level. This resulted in some faculty orders being blocked while the Library's collection could not provide them with the articles due to cancelled subscriptions, incomplete runs, or other reasons. The chronological coverage of the CISTI Source database was another issue. The database covers materials from 1993, but faculty may need information published earlier.

A change in strategy was required. To remove the mental barrier of saving the CISTI Source option for future or urgent needs, the upper limit of ordering 15 articles per person was removed. As CISTI Source has 35 per cent social sciences and humanities content, the service was extended in April 2002 to all faculty instead of being restricted to the science and engineering departments. To zero in on the heavy researchers, flyers were sent out in January 2002 to faculty who had recently obtained research grants or were actively engaged in research projects.

The decision was then made to appeal to a new group of users who place higher priority on speed, convenience and control over the ordering process. In September 2002, the service was extended to graduate students and in May 2003 to research assistants, and then to fourth year undergraduate students in September 2003. Over 43 faculty users were registered between the period of November 2001 and June 2002. A higher number of graduate students have participated since September 2002, bringing the combined total of registrants to 115 at the end of January 2004. Ordering of articles has doubled since the service was introduced to graduate students (Figure 1).

It became clear that focusing only on speed of delivery to faculty was inadequate. Coincidentally, CISTI Source changed their marketing strategy to offer free Alerts to document delivery registrants. The Library quickly seized the opportunity to repackage the marketing plan - emphasizing that the CISTI Source service is the ultimate research tool, combining in one source the Alerts, the link to full-text resources (via our catalogue links) and document delivery at the time of needs. 
Improving the linkage of local holdings to CISTI Source database relies on an overhaul of Ryerson's periodical catalogue records and converting them to the MARC format. The process is time-consuming and labour-intensive. The Serials Solution software has recently been acquired to enhance the linkage of journal titles to electronic full texts. These initiatives should eventually improve the automatic checking of library holdings against the CISTI Source database, thereby reducing one of the biggest frustrations faced by users.

In spite of some imperfections, the CISTI Source service has been well received by Ryerson users. Two small-scale surveys on user satisfaction were carried out in February and July 2003. Over 30 per cent of the registrants responded. The respondents were overwhelmingly in favour of the service (over 93 per cent ranking it in the top two categories on a scale of 1-5). These users were most appreciative of the speed and convenience. (75 per cent also chose “outstanding” for “ease of placing orders” and “document delivery time”).

While Ryerson's CISTI Source project may not be truly unmediated, partly because of copyright restrictions, the satisfaction rate from the survey respondents and the steady increase in ordering indicate that the main objectives were achieved:

- to provide users with an alternative means of electronically ordering journal articles other than ILL;

- $\quad$ to provide ease and convenience of 24/7 ordering;

- to guarantee fast turnaround time (48 hours) of journal article delivery, not possible with ILL;

- to provide users with more control of their request and borrowing process and flexibility in planning their research; and

- to raise the profile of the ILL department in the new, redefined relationship between the Library, education and the users.

\section{Rapid access to collection by electronic requesting}

The most recent large-scale initiative of OCUL is the implementation of "rapid access to collections by electronic requesting” (RACER; http://racer.scholarsportal.info/). This is an ILL management system using virtual document eXchange (VDX) software developed by FretwellDowning in the UK. The ability for end-users to search across 20 library catalogues simultaneously and in real-time is a breakthrough not only for end-users but also for ILL staff. The RACER database includes the virtual catalogue of Ontario universities and selected world catalogues such as AMICUS (an information resource developed and maintained by the National Library of Canada for libraries and researchers), Library of Congress, British Library, National Library of Canada, RLG RLIN (the Research Libraries Information Network, an internationally available bibliographic information system used with RLG's Library Resources) and Southern Ontario Library Services (SOLS, Canada). The capacity for bibliographic information derived from these searches to auto-populate the ILL forms has finally achieved a user-centred vision. The real-time e-mail alerts sent to users informing them of arrivals, non-supply and local holdings as well as users' ability to monitor the status of their requests are features that are absent in the DOS-based AVISO system that was created in the early 1990s. Finally, the idea described by Mary Jackson, the "standards that permit intersystem transfer of requests", is closer than ever 
before (Jackson, 1998a, b). Since 18 June 2003, Ryerson Library has been using the VDX technology to communicate with other modified ISO and Generic Script systems. Soon there may be ISO direct requesting to other resource-sharing systems such as OCLC and RLG's ILL Manager, thereby reducing the remaining hurdles in the way of transferring requests.

RACER is the most ambitious ILL project yet for Ontario universities. No OCUL ILL project has been as complex and involved as many levels of staff from participating institutions. It has also been the longest, taking almost three years from its inception to actual implementation in 2003. Without the government funding from Ontario Innovation Trust (OIT), Ryerson and many other Ontario universities would never have had the chance to acquire a system as sophisticated as VDX. The regional project was funded by a five-year grant from OIT in 2001 (for hardware, software and site licensing) and contributions from OCUL members (for salaries, administration and evaluation).

The idea of collaborative acquisition and implementation of a new ILL system is the result of a general desire of Ontario university libraries to replace their existing ILL systems, which are mainly AVISO. The opportunity for collaboration came in 1999 when the University of Toronto, the largest university in Canada, was reviewing ILL software and invited other OCUL members to participate in evaluating ILL products. The OCUL ILL mangers voted unanimously at a meeting in March 2000 to recommend to the OCUL Directors the adoption of the VDX software across OCUL.

The contract between the University of Toronto and Fretwell-Downing was expanded to include all OCUL members. Acting as the central service provider for the whole OCUL group, the University of Toronto had to acquire servers and other necessary hardware in the following year. In 2002, a project team of specialists was recruited to plan, manage, train and provide support to OCUL members. ILL managers from OCUL volunteered to serve on various teams, responsible for collecting data on policies, external locations, statistical reports and systems, to help lay the groundwork for the global settings and defaults. When approaching the "production" stage, a public services team was formed in April 2003 to deliberate on end-user instruction and training. Numerous surveys were conducted aimed at confirming the OCUL and location specific configuration settings. These included questions on Z39.50, external locations, and policies.

In 2002, the Z39.50 catalogue was launched. In order that VDX could send and receive Generic Script ILL requests to the many other Canadian institutions that do not have ISO compliant systems, OCUL made a special deal with Fretwell-Downing to develop a translator program (called the Generic Script driver). Both OCUL and Fretwell-Downing staff spent substantial time on testing and development work to validate the "translation" functions. OCUL libraries had to undergo training at different stages and practice communication with each other for months, testing the generation of "Rota" (a list of potential responders or request routing), the display of local availability, the automatic Alert sent to users notifying arrival of materials, cancellation of requests and availability in local collections, and the performance of the system under stress when it is being used simultaneously by participating institutions.

Some compromises of local preferences are inevitable in any collaboration. In the main, consensus has been reached for policy defaults and global settings, which include turn-around 
time expectations, renewal policies and selections of holdings for the DocFind matching. (The Rota is built by a processor or ILL driver called DocFind.) When it was deemed desirable, OCUL's Tactical Implementation Group (TIG) also negotiated with other ILL consortia for a global reciprocal agreement or a common service policy between them and OCUL members.

Other resource-sharing partners have been very helpful. For example, the National Library of Canada provided a copy of the National ILL Directory so that RACER could begin with a fairly complete database of all potential Canadian resource-sharing partners.

Convenience to Ryerson users is undoubtedly enhanced by the new system, especially when compared with the former AVISO system (Table I).

At this initial stage of implementation, the process is mediated by OCUL staff, although it is possible for end-users to directly send the requests to lending locations without the intervention or monitoring by staff. The implementation is being staged in different phases across OCUL members in 2003/2004. Ryerson was among the first group to go into production on 18 June 2003. Both ILL staff and users went through a big learning curve during the transition. Confusion about the self-registration process was the first hurdle for users. Then came the misunderstanding of VDX or ISO terminology (e.g. idle, shipped, check manual, automediated) when users were checking their own profiles. Users have not yet taken full advantage of the new capability of bibliographic searching and requesting ILL within the same system; there is the tendency to separate the process and use blank ILL forms exclusively for requests. Staff are groping with a changed workflow. They are discovering what the new technology can do or cannot do in reality, learning to strike a balance between their own preferred practices with the global policies and defaults, trying out temporary e-mail workarounds to address some system incompatibilities, and answering numerous questions from non-VDX libraries as well as enquiries from end-users about the new ways of communication.

System interoperability is a big challenge. While on the one hand, the RACER system has seamless requesting and receiving with ISO systems - CISTI, National Library of Canada and the British Library (using the ARTISO system), the Generic Script (GS) driver and e-mail workarounds were created to communicate with the many resource-sharing partners, who are still using the DOS-based AVISO or have no systems at all. ILL staff were inundated with the new task of giving instructions to these institutions, directing them to use an OCUL developed Web request form. Staff had to communicate with the OCUL's TIG to ensure these locations had proper records in the VDX database. Staff have commented on the workflow issues associated with receiving some messages from GS sites into their RACER e-mail administrative accounts instead of the messages directly parsing into VDX. The problem is usually associated with anomalies in the specific library's set-up of their GS system. TIG and Fretwell-Downing staff have identified the system anomalies on a case by case basis with the other library's systems staff to adjust their GS set-up. TIG has also striven to improve the accuracy and reliability of Docfind results, as $\mathrm{Z}$ targets vary from vendor to vendor. Members of the RACER public services team have been working hard since implementation to improve the end-user interface, making it more intuitive, user-friendly and functional. Added to these efforts will be a new VDX 2.4 release in 2004, which promises more service enhancements. 
The OCUL RACER system has demonstrated the emphasis on a user-centred approach to the ILL process. The extensive collaboration between the members in planning and executing the project is an example of how a consortium can help to achieve an end which is difficult to be met by individual efforts. Interlibrary loan itself is a partnership process, enabling reciprocal borrowing and lending. The forming of different consortia, regional or functional, to reduce cost, or to share resources, is a new definition of the partnership, which few academic libraries can afford to ignore.

\section{Conclusion}

Interlibrary loan is a costly and complex activity, and at a small university like Ryerson (with a small collection and an increasing demand), plays a large role in the delivery of library services. The ever-volatile global information ownership and access environment requires the library to participate in the implementation of new software and engage in the latest consortial endeavours in order to deliver timely and cost-effective services.

These three initiatives: shared netLibrary eBooks, CISTI Source Document Delivery, and the RACER VDX ILL system, have greatly enhanced Ryerson Library's ability to satisfy its users with resources beyond the Library's limited collection. They have empowered the user to access resources more directly, from remote locations, and at their own time and convenience. Ryerson will continue to work with OCUL and other Canada-wide (or even international) initiatives to expand unmediated access to electronic resources, and to work towards making Ryerson's interlibrary loan and document delivery services truly unmediated.

CISTI Source Orders 2002-2003

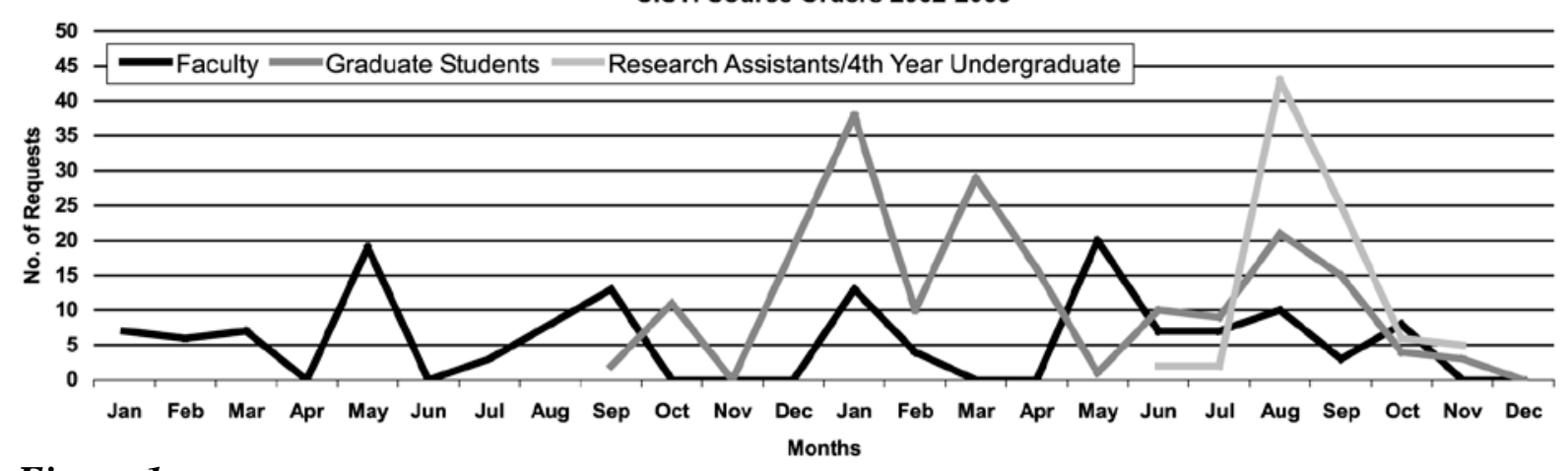

Figure 1 
Table I

\begin{tabular}{|c|c|}
\hline AVISO & VDX \\
\hline $\begin{array}{l}\text { User filled in a blank Web form on the Library's innovative } \\
\text { integrated system }\end{array}$ & $\begin{array}{l}\text { User has the additional choice of bibliographic search across } \\
\text { library holdings and results auto-populate the ILL request } \\
\text { form, without rekeying }\end{array}$ \\
\hline $\begin{array}{l}\text { User had to search local library holdings and other catalogues } \\
\text { separately }\end{array}$ & $\begin{array}{l}\text { User can search a virtual catalogue and holdings } \\
\text { simultaneously }\end{array}$ \\
\hline User could not monitor the status of their request & $\begin{array}{l}\text { User can monitor the status of their request - whether } \\
\text { it is in process, or cancelled }\end{array}$ \\
\hline $\begin{array}{l}\text { User had to communicate with staff in person or by phone to } \\
\text { find out the status of their request }\end{array}$ & $\begin{array}{l}\text { An automatic Alert is sent to the user's e-mail account, } \\
\text { informing them that materials have arrived, requests } \\
\text { cancelled or available in local holdings }\end{array}$ \\
\hline $\begin{array}{l}\text { Staff had to rekey users' requests in AVISO from the innovative } \\
\text { system. Requests sent/received through AVISO were } \\
\text { stored overnight on local computers before batch dispatched } \\
\text { to other locations }\end{array}$ & $\begin{array}{l}\text { Users' requests are received in real-time by staff and sent in } \\
\text { real-time to lending locations }\end{array}$ \\
\hline
\end{tabular}

\section{Table I}

\section{References}

Cannon, E., Watson, S. (2001), "Taking e-books for a test drive", Computers in Libraries, Vol. 21 No.3, pp.25-7.

Conhaim, W (2003), "E-books are not dead yet", Information Today, Vol. 20 No.1, pp.40-1.

Fuller, D.H. Jr (2002), "Distance learning and interlibrary loan: a look at services and technology", Journal of Interlibrary Loan, Document Delivery \& Information Supply, Vol. 12 No.4, pp.15-25.

Jackson, M.E. (1998a), "Loan stars. ILL comes of age", Library Journal, Vol. 123 No.2, pp.447.

Jackson, M.E. (1998b), Measuring the Performance of Interlibrary Loan Operations in North American Research and College Libraries, Association of Research Libraries, Washington, DC, .

Littman, J. (2002), "A preliminary comparison of electronic book and print book usage in Colorado", Colorado Libraries, Vol. 28 No.3, pp.39-41.

Lynch, M. (2001/2002), "Nylink's shared collection: a collaborative introduction of a new technology", Against the Grain, Vol. 13 No.6, pp.26-30.

McDonald, E. (2003), "The (long and winding) road to a provincial e-book collection", Access, Vol. 9 No.2, pp.10-13.

Row, J., Shrode, F., Smith, R. (2001), "Across the disciplines: does subsidized document delivery meet the challenges?", Collection Management, Vol. 26 No.2, pp.13-29. 
Ryerson University Library (2000), Ryerson Library Materials Availability Survey, available at: www.ryerson.ca/library/info/mas/index.html, www.ryerson.ca/library/info/mas/index.html

Stabler, K. (2002), "Benchmarking interlibrary loan and document delivery services: lessons learned at New Mexico State University", Journal of Interlibrary Loan, Document Delivery \& Information Supply, Vol. 12 No.3, pp.57-73. 